\title{
ADSORPTION STUDIES OF SOME DYES ON ACACIA CONCINNA POWDER
}

\author{
Geetha K.S ${ }^{1}$, Belagali S.L $\mathbf{L}^{2}$ \\ ${ }^{I}$ Department of Environmental science, University of Mysore, Mysuru, Karnataka, India-570006 \\ ${ }^{2}$ Department of Environmental science, University of Mysore, Mysuru, Karnataka, India-570006
}

\begin{abstract}
The low cost activated carbon from Acacia Concinna was processed by treating with $2 \% \mathrm{HCl}$ and $2 \% \mathrm{NaOH}$. The treated Acacia Concinna (Shikakai powder) was then roasted to get activated carbon. The influence of parameters like $\mathrm{pH}$, concentration, dose and contact time were studied on adsorption of activated carbon for Congo red, Rhodamine-B, Crysoidine, Bismark brown and Titan yellow. The adsorption capacity of activated carbon was found to be 97, 98, 95, 98 and 96\% respectively at pH 2 and contact time 24-48 hrs for all the dyes. The effect of concentration indicated that, as concentration increases adsorption decreases, hence increase in dose amount increases the adsorption. The data obtained through batch adsorption study was applied for Langmuir, Freundlich and Dubinin-Radushkevich $(D-R)$ isotherms. The curve was linear for all the three isotherms and correlation coefficient $\left(R^{2}\right)$ was $0.92,0.970$ and 0.977 respectively indicating that the developed model was favourable.
\end{abstract}

Keywords: Adsorption, Acacia Concinna, dyes, isotherms, XRD.

\section{INTRODUCTION}

Dyeing and finishing are some of the important industrial processes in textile, paper making and leather manufacturing industries. The effluents from dye manufacturing and certain other industries like textile, pulp and paper, dyeing, printing and leather contain small amounts of dyes. They impart colour to water thereby lowering its aesthetic values (Geetha and Belagali, 2011).

Dyes have complex molecular structures, they are stable to light, heat and resistant for biodegradation. To overcome this problem, various methods are developed like, electro chemical, membrane filtration, reverse osmosis, flocculation - coagulation, biological treatment and photocatalytic degradation. All these conventional methods are not feasible due to economic considerations.

Adsorption has been found to be the suitable method for the removal of color of the industrial waste water. Activated carbon has high adsorptive capacity. This is due to the extensive internal porous structure formed in activation process. But commercially activated carbon, polymeric resin, chitin, silica are quite expensive. As a result, a search for several non conventional low cost adsorbents from agricultural and industrial wastes was planned (Geetha and Belagali, 2010).

Many investigators have explored some low cost adsorbent materials. These investigations include the use of Coconut husk powder (Prasad and Sarveswara Rao, 2009), Rice husk (Waheed. S. Deshmukh, 2009), Garlic husk (Geetha and Belagali, 2010), Areca nut shell (Geetha et al., 2009), etc.

In this present study, we have used the adsorbent from the plant material SHIKAKAI POWDER.

\section{MATERIALS AND METHODS}

\subsection{Materials}

Preparation of activated carbon from new adsorbent, Shikakai powder: The Shikakai powder is treated with $2 \%$ $\mathrm{NaOH}$ and $2 \% \mathrm{HCl}$ for half an hour, then the powder is washed thoroughly and $\mathrm{pH}$ was maintained at neutral condition, filtered, dried then roasted to get activated carbon. It is stored and used as adsorbent. Sieved in ordinary siever of $2 \mathrm{~mm}$ diameter for obtaining $2 \mathrm{~mm}$ diameter particle size.

Preparation of dye solution: $0.01 \mathrm{mg}$ of dye (RhodamineB, Crysoidine-R, Congo red, Bismark brown and Titan yellow) were weighed and dissolved in $100 \mathrm{ml}$ of distilled. water to get $100 \mathrm{ppm}$ of solution. Then, it is diluted to required concentration. All the chemicals used were of Analar grade.

Adsorption isotherms: In order to determine the sorption potential of adsorbent, the study of sorption isotherms was essential in selecting an adsorbent for the removal of the dyes. The adsorption data was studied with the DubininRadushkevich (D-R), Freundlich and Langmuir isotherms (Adamson 1960).

Freundlich isotherm: $\log q_{e}=\log K+\left(1 / n \log C_{e}\right)$

Langmuir isotherm: $\left(C_{e} / q_{e}\right)=\left(1 / Q_{0} b\right)+\left(C_{e} / Q_{0}\right)$

Dubinin-Radushkevich: $\log q_{\mathrm{e}}=\log \mathrm{q}_{\mathrm{m}}-\beta E^{2}$

where $\mathrm{q}_{\mathrm{e}}$ is the amount of dye adsorbed per unit mass of adsorbent at equilibrium (in $\mathrm{mg} / \mathrm{gm}$ ), $\mathrm{K}$ and $\mathrm{n}$ are respectively the measures of sorption capacity and intensity of adsorption, $\mathrm{C}_{\mathrm{e}}$ is the equilibrium concentration of dye (in 
$\mathrm{mg} / \mathrm{L}), \mathrm{Q}_{\mathrm{o}}$ and $\mathrm{b}$ are the Langmuir constants indicating the sorption capacity (in $\mathrm{mg} / \mathrm{gm}$ ) and energy of adsorption (in $\mathrm{gm} / \mathrm{L}$ ) respectively from the slope and intercept.

Kinetics of the adsorption: The Kinetics of adsorption of dye was studied by testing the first order kinetics equation proposed by Kannan and Vanamudi (1991) which is given below:

$$
\mathrm{k}=(2.303 / \mathrm{t}) \log \left(\mathrm{C}_{\mathrm{o}} / \mathrm{C}_{\mathrm{t}}\right)
$$

where $\mathrm{C}_{\mathrm{o}}$ and $\mathrm{C}_{\mathrm{t}}$ are concentrations of dyes at zero time and at time $t(\mathrm{~min})$. The values of $\log \left(\mathrm{C}_{\mathrm{o}} / \mathrm{C}_{\mathrm{t}}\right)$ were found to be linearly correlated with the contact time for different dyes/metals.

Batch experiment: Dyes adsorption experiments were conducted in batch mode with $50 \mathrm{ml}$ stock solution. The variables studied were adsorbent dose, concentration of adsorbate, $\mathrm{pH}$ and contact time. The mixture was observed for adsorption process after keeping the solutions for adsorption to take place.

- $\quad$ For effect of adsorbent dose, five numbers of $50 \mathrm{ml}$ samples of $50 \mathrm{ppm} / \mathrm{L}$ dye solutions were taken in beakers and $0.25-1.5 \mathrm{~g}$ of dose of adsorbent was added and studied for adsorption.

- Constant dose of adsorbent (0.5 g) was separately added to $50 \mathrm{ml}$ samples with different concentrations of dye solutions $(10,20,30,40 \& 50 \mathrm{ppm})$ in 5 beakers, at room temperature and studied for the effect of concentration.

- $\quad$ Five numbers of $50 \mathrm{ml}$ samples of dye solutions from 10-50 ppm and varying doses of adsorbents from $0.25-1.5 \mathrm{~g}$ were added in series. Then, the correlation of the two variables was studied.

- $\quad$ For the effect of contact time, $0.5 \mathrm{~g}$ of adsorbent dose was added to $50 \mathrm{ml}$ of $10 \mathrm{ppm}$ dye solution and hourly once the rate of adsorption was studied.

\section{RESULTS AND DISCUSSION}

Table-1: Adsorbent characteristics:

\begin{tabular}{|l|l|}
\hline Property & $\begin{array}{l}\text { Shikakai } \\
\text { powder(adsorbent) }\end{array}$ \\
\hline Moisture Content & Dry powder \\
\hline $\mathrm{pH}$ & Neutral \\
\hline Particle size & $2 \mathrm{~mm}$ \\
\hline Decolourizing power & More than $90 \%$ \\
\hline Carbon content & $99 \%$ \\
\hline
\end{tabular}

Effect of dose: The results show that, as dose increases, adsorption increases.

Effect of concentration: The results show that, as concentration increases, adsorption increases.

Effect of contact time: The results show that, as the time increases, adsorption increases.
Effect of dose Vs Concentration: The results indicate that, the dose and the concentration of all the dye solutions, for all the adsorbents are co-related to each other.

Effect of particle size: The adsorption of all the dyes was maximum in the particle size $2 \mathrm{~mm}$ compared to the particle size 4 and $6 \mathrm{~mm}$ respectively.

Table-2: Adsorption isotherms for removal of dyes from aqueous medium:

\begin{tabular}{|c|c|}
\hline Parameter & Shikakai powder \\
\hline \multicolumn{2}{|l|}{ Freundlich isotherm: } \\
\hline Slope(1/n) & 1.050 \\
\hline Intercept $(\log k)$ & 0.175 \\
\hline Correlation co-efficient (r) & 0.920 \\
\hline \multicolumn{2}{|l|}{ Langmuir isotherm: } \\
\hline Slope $\left(1 / Q_{0}\right)$ & 0.220 \\
\hline Intercept & 2.00 \\
\hline Correlation coefficient $(r)$ & 0.972 \\
\hline \multicolumn{2}{|l|}{ Kinetics of adsorption: } \\
\hline $10^{2} \mathrm{k}\left(\mathrm{min}^{-1}\right)$ & 0.059 \\
\hline r-value & 0.974 \\
\hline \multicolumn{2}{|l|}{ D-R isotherm } \\
\hline$q_{\max }(\mathrm{mg} / \mathrm{g})$ & 10.6 \\
\hline $\mathbf{E}(\mathbf{k J} / \mathbf{m o l})$ & 2.16 \\
\hline $\mathbf{R}$ & 0.977 \\
\hline
\end{tabular}

Table-3: percentage adsorption of dyes from aqueous

\begin{tabular}{|l|l|}
\multicolumn{2}{|c}{ medium: } \\
\hline Dyes & $\begin{array}{l}\% \text { adsorption }=\underline{\mathbf{C}}_{0}-\mathbf{C}_{\mathrm{e}} \\
\times \mathbf{1 0 0} \\
\mathbf{C}_{\mathbf{0}}\end{array}$ \\
\hline Cango red & $\mathbf{9 7 \%}$ \\
\hline Rhodamine-B & $\mathbf{9 8 \%}$ \\
\hline Crysoidine & $\mathbf{9 5 \%}$ \\
\hline Bismark brown & $\mathbf{9 8 \%}$ \\
\hline Titan yellow & $\mathbf{9 6 \%}$ \\
\hline
\end{tabular}




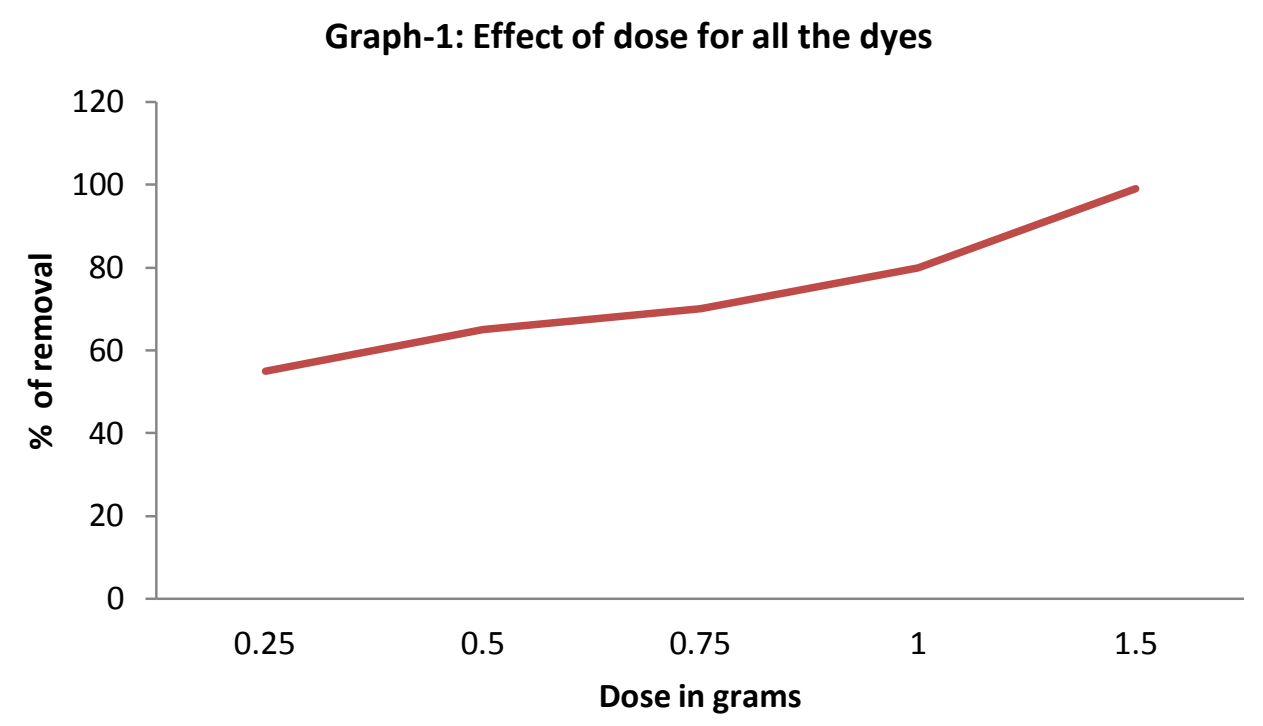

Fig-1: Graph showing effect of adsorbent dose:

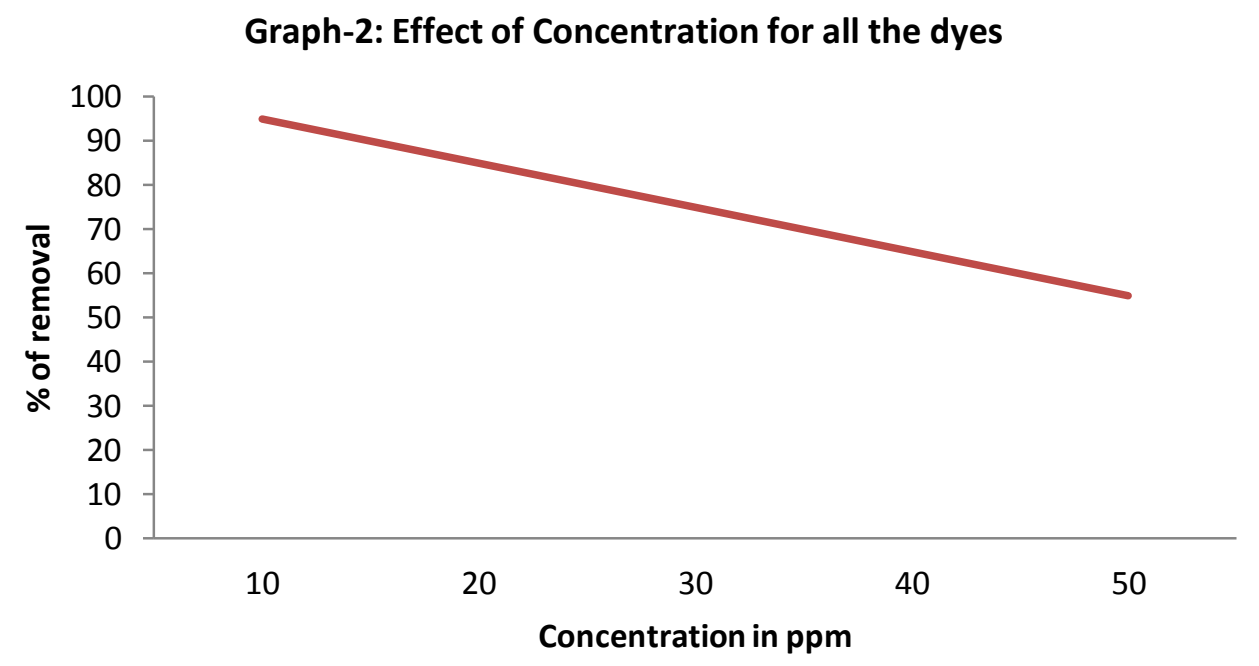

Fig-2, Graph showing effect of Concentration

\section{Graph-3, Effect of contact time for all the dyes.}

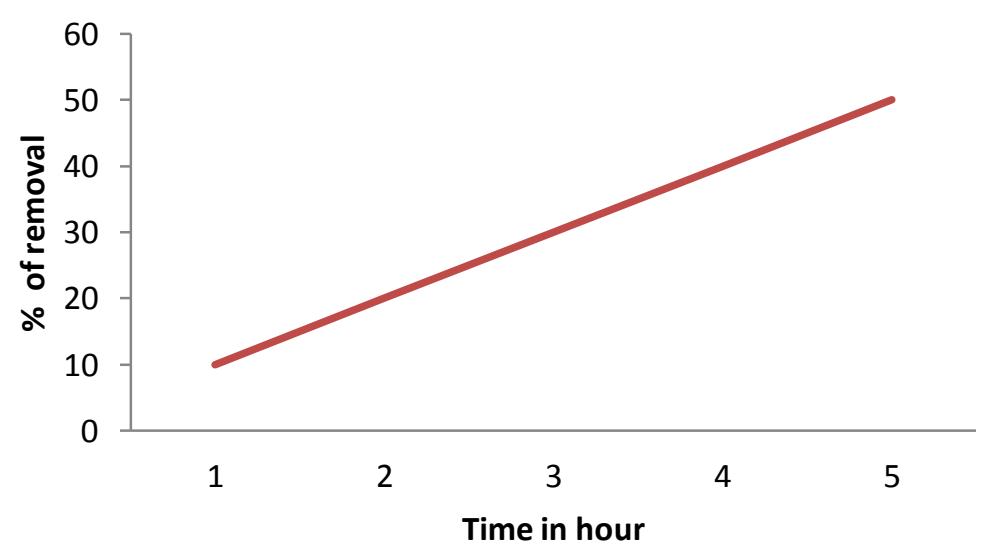

Fig-3, Graph showing effect of Contact time 


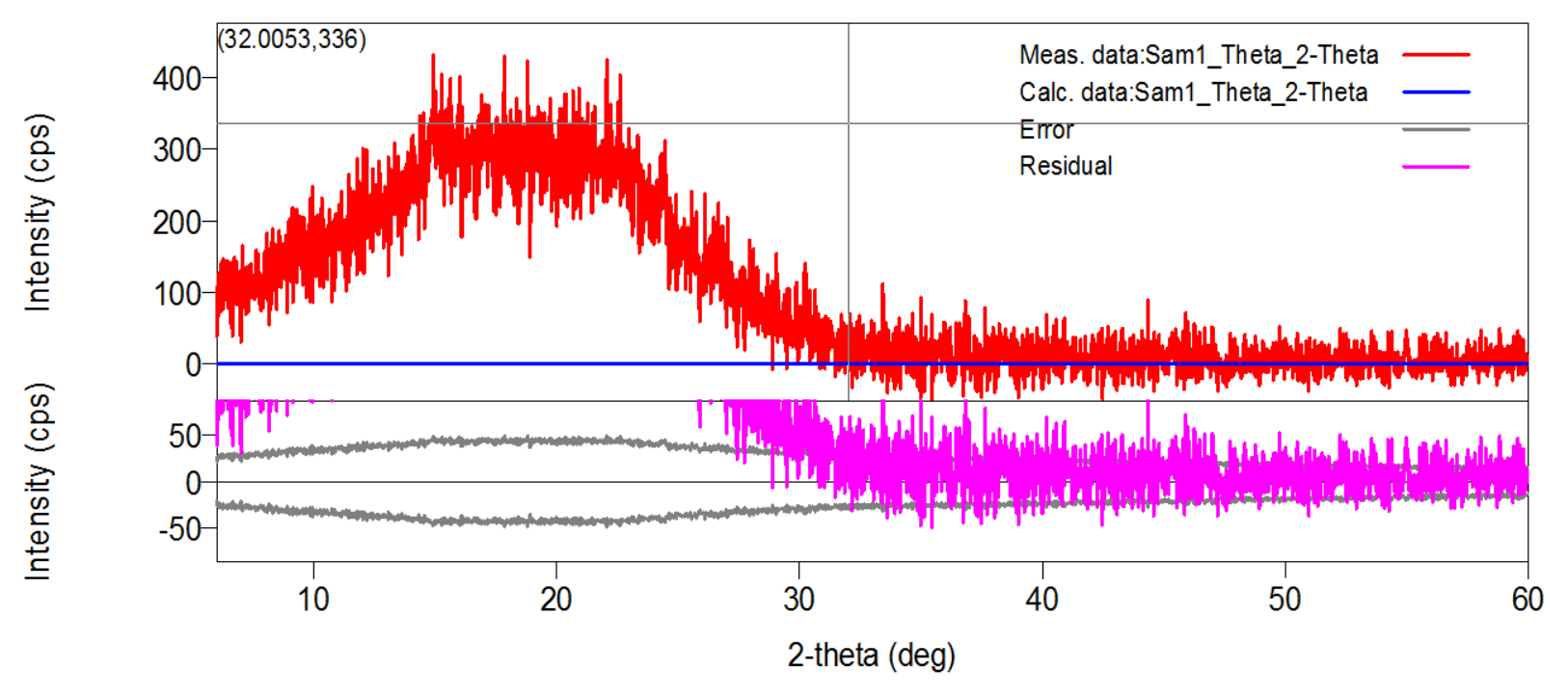

Fig-4: XRD spectra for Shikakai powder (Adsorbent).

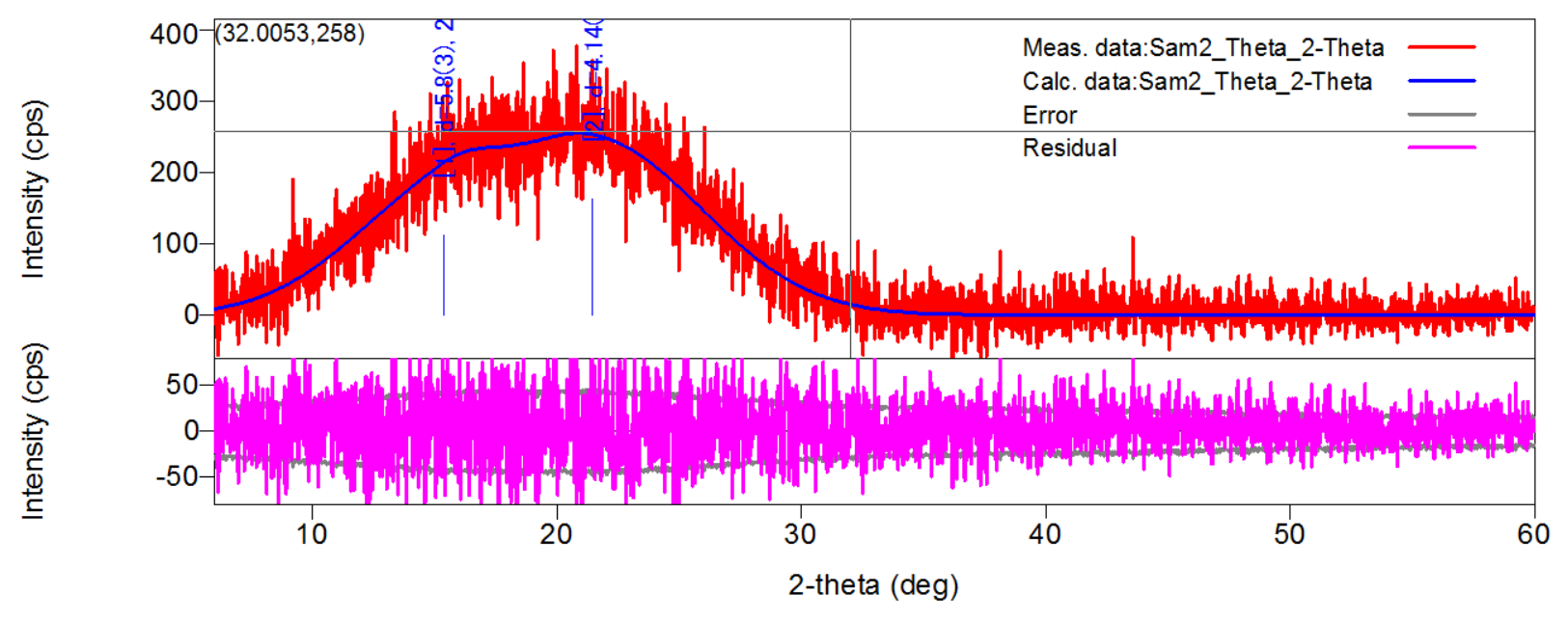

Fig-5: XRD spectra for Crysoidine dye on Shikakai powder.

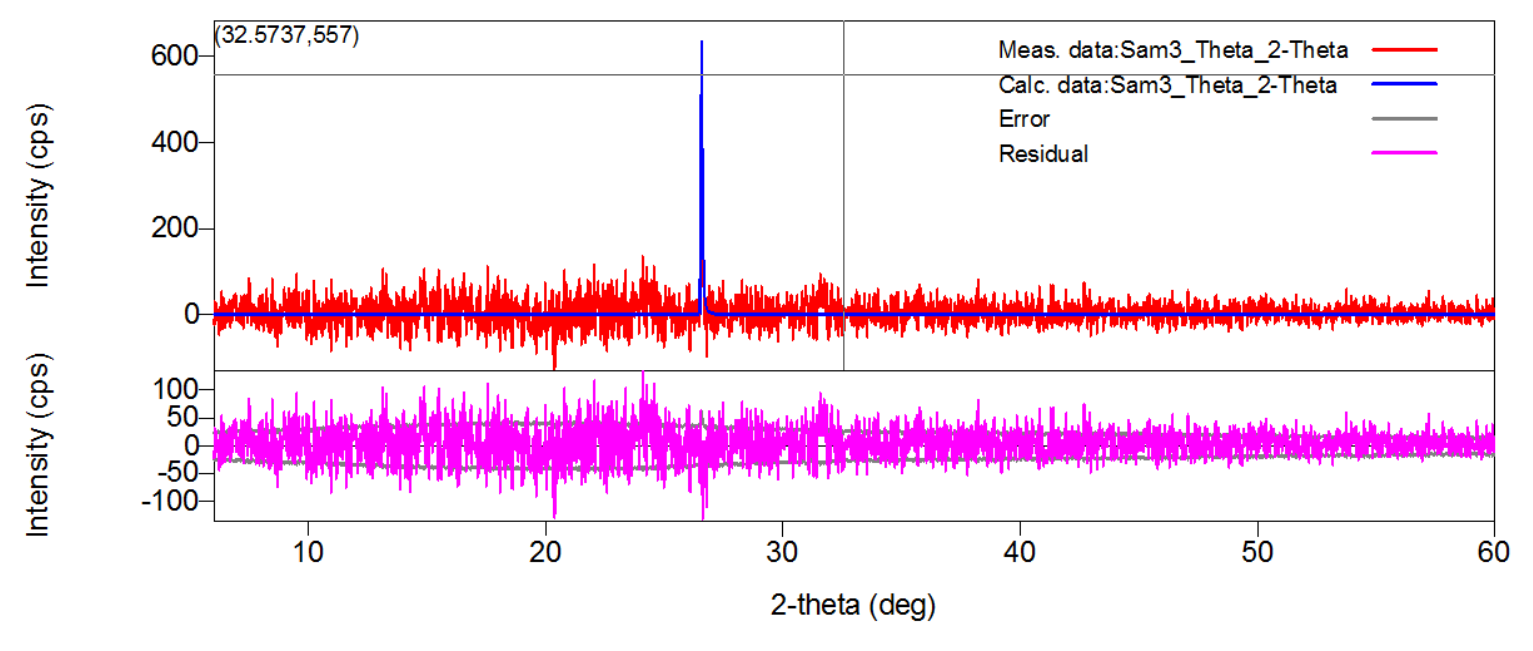

Fig-6: XRD spectra for Rhodamine-B dye on Shikakai powder. 


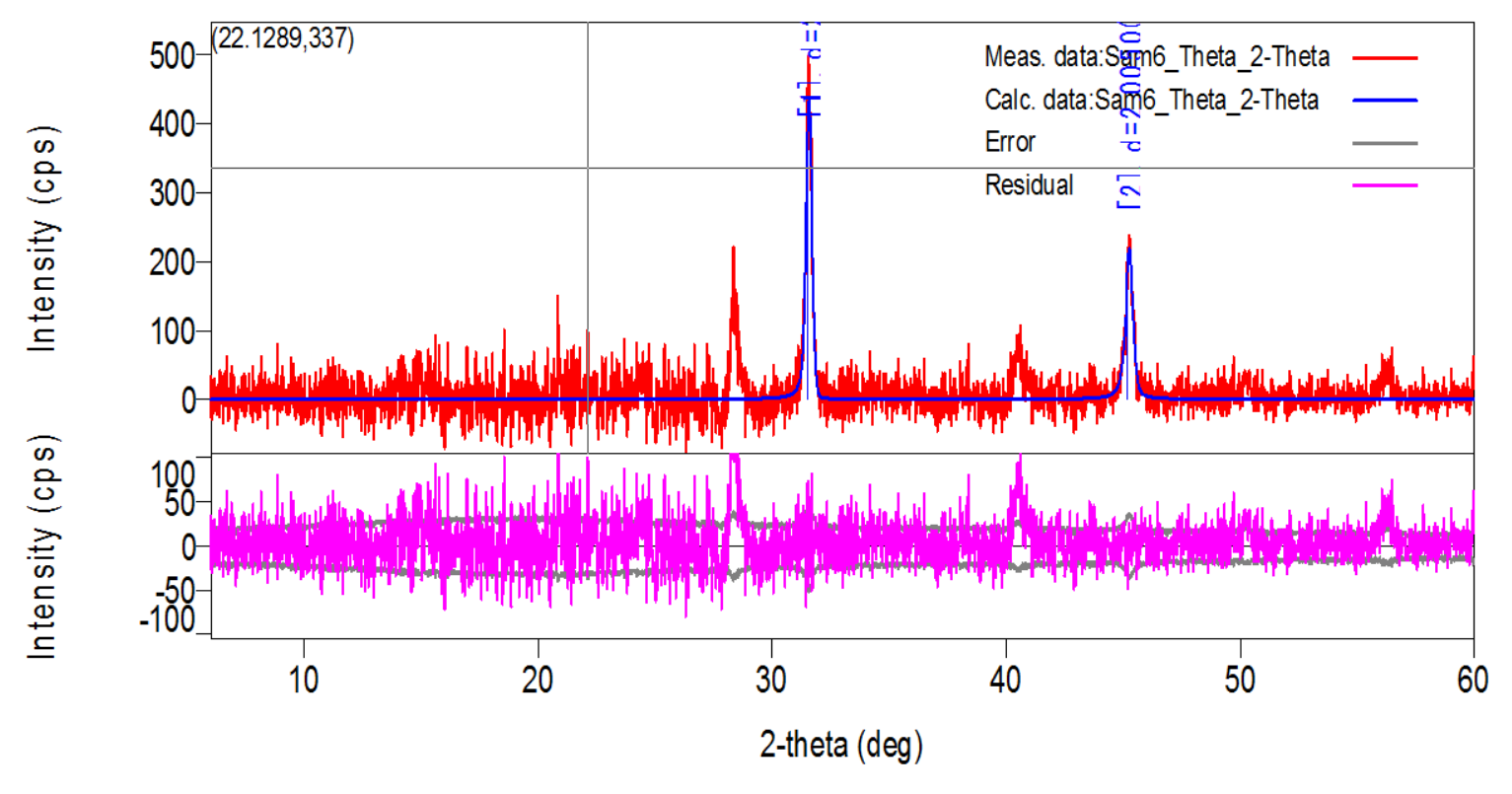

Fig-7: XRD spectra for Cango red dye on Shikakai powder.

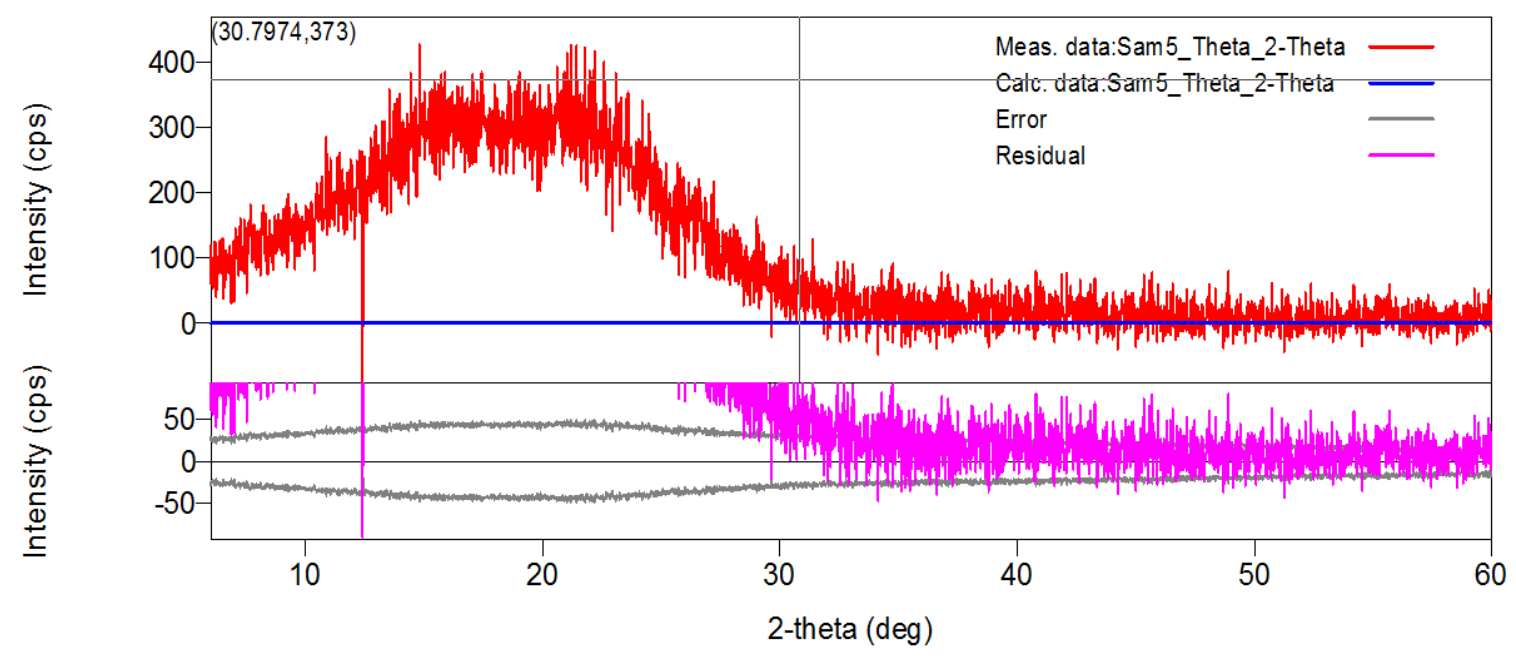

Fig-8: XRD spectra for Titan yellow dye on Shikakai powder.

\section{CONCLUSION}

The kinetic value $\left[\left(10^{2} \mathrm{k} \min ^{-1}\right)(0.059]\right.$ for the adsorbent shows the model to be first order. $\mathrm{R}$ value lies within one which indicates the model developed is favourable. The models obey Freundlich and Langmuir isotherms and linear correlation between two variables (0.977). The DubininRadushkevich (D-R) isotherm model shows the process is known to follow physical adsorption if value is less than $8 \mathrm{~kJ} / \mathrm{mol}$. Particle size of adsorbent was $2 \mathrm{~mm}$ for higher adsorbing capacity. The maximum adsorption was found to be at $\mathrm{pH} 2$ with particle size of $2 \mathrm{~mm}$ diameter of adsorbent. The developed Shikakai powder adsorbent is very good adsorbent and found to be economically favourable activated carbon.

\section{REFERENCES}

[1] Adamson A.W, Physical chemistry of surfaces, Interscience Publ. Inc., New York., 1960.

[2] Geetha K.S and Belagali S.L, Removal of heavy metals and Dyes Using low cost adsorbents from aqueous medium-A review, IOSR journal of Environmental Science, toxicology and food technology,2013, 4(3),56-68.

[3] Geetha A, Shivkumar P, Sujatha M. Palaniswamy P.N and Somasundaram T, Adsorption of Acid blue from an aqueous solution onto activated Areca Nut shell carbon, Equilibrium, Kenetic and thermodynamic studies, Res. J. Chem. Environ., 2009, 13(1),52-58. 
[4] Geetha K.S and Belagali S.L, Adsorption studies of plants Base oil and Mineral Oils on tea powder waste, International Journal of Scientific and Research Publications, 2013, 3(1),1-7.

[5] Geetha K.S and Belagali S.L, Removal of dyes and Heavy metals using Garlic husk. Res.J.Nat. Env.Poll.Tec., 2010,9(2),323-327.

[6] Geetha K.S and Belagali S.L. Application of Natural adsorbents for dyes and Industrial effluents, The Ecoscan, 2011, 5(1\&2), 89-93.

[7] Geetha K.S and Belagali S.L., Dyes adsorption study on natural adsorbent Chewing tobacco, The Ekologia, 2011. 11(1-2). 47-54.

[8] Kannan $\mathrm{N}$ and Vanangamudi a, a study on the removal of Chromium (VI) by adsorption on lignite coal. Indian J. Env. Prot, 1991, 11(4), 241-245.

[9] Kelchandra Singh K, Vishnu M, Matta, Manihar Sharma B and Kh. Usha, Seasonal variation of some trace metals in the sediments of the Mondovi River of Goa, The Ekologia, 2009, 9(1-2),87-94.

[10] Prasad A and Sarveswara rao S, Removal of copper using micro size coconut husk powder: equilibrium and kinetics studies, Res. J. Nat. Envi.Pollu.Tech., 2009, 8(2), 389-394.

[11] Rao M, Parwate A.V and Bhole A.G, Heavy metals removal by adsorption using Bagasse and modification to Helfferich model. Environ. Poll. Control, 6(4), 6-13.

[12] Sudha R and Srinivasan K, Removal of Ni(II) from plating Wastewater by Citrus Limettioides Peel, Coromandal Journal of Science, 2013, 2(2), 41-47.

[13] Waheed Deshmukh S, Attar S.J and Waghmare M.D, 2009, Investigation on sorption of fluoride in water using rice husk as an adsorbent. Res. J. Nat. Env. Poll. Tech., 2009, 8(2), 217-223. 